\section{Dates}

\section{for your aliany}

If you have an event you want featured in 2019, email the Editor: caroline.holland@nature.com

\section{The Orthodontic National Group Spring Study Day}

March 2, Birmingham, RCS (Ed) Regional Centre, 85-89 Colmore Row, B3 2BB

9am-4pm, 5 hours verifiable CPD Speakers include Marwa Maarouf, George Jones, Sheena Kotecha and Jane Bonehill. Facebook.com/ orthodonticnationalgroup or wwW. orthodontic-ong.org.

\section{BSP 2019}

The 2019 BSP Conference takes place in Brighton 24-26th April Details here http://www. bsperio.org.uk/events/info/bspconference-2019.

\section{The ADI Team Congress 2019}

May 2-4, the Edinburgh Internationa Conference Centre (EICC)

The Future of Dental Implantology: Techniques-Technology - Teamwork. An event for experienced dental professionals as well as those who have just started out with dental implants, the Congress gives the chance to gain up-todate knowledge, make new discoveries, network with like-minded individuals and make new contacts. The event will see a major trade exhibition hosting a wide selection of stands where professionals can experience new products and discover the latest advancements. For more information, please visit www.adi.org.uk.

https://www.adi.org.uk/events/ events.php.

\section{National Orthodontic Therapist Day}

May 17, Mandec, Manchester

Speakers: David Waring, Steve Chadwick, Simon Littlewood, Amy Gallacher, Richard Needham, Badri Thiruvenkatachari, Ovais Malik. Limited spaces, book early: www. bos.org.uk.

\title{
EVERYTHING I DO, I DO FOR YOU
}

A $\mathrm{n}$ inspirational talk by Dr Rosie Tope Aon the topic of caring for patients with dementia was one of the highlights of the most recent meeting of the British Society of Gerodontology entitled: The future's bright for older people and oral care in the UK?

A trustee of Carers UK, a nurse, an academic researcher and a campaigner for people living with dementia and their families, Dr Tope gave an outline of the resources she is developing to assist communications with dementia patients.

'At least 25\% of you will become a longterm carer,' she said, urging her audience to understand that dementia is an umbrella term. There are many different kinds with Alzheimers being the most common.

When discussing the challenges faced by carers, she speaks from experience. Poignantly, but with great humour, she told the story of living with her late husband Roy, who suffered with dementia for 13 years.

'I used to think I was empathetic. Until you are looking after someone $24 / 7$, you have no idea of what it's like to be a carer.' For nine of the 13 years of his illness, she was able to care for him at home, she said, as he would have done for her, until he became too unwell and difficult to care for when he went into a secure unit in hospital.

Roy self-diagnosed in 2001. He had been getting increasingly muddled and then one day he said to his grand-child: 'I have absolute compliments in you.' The threeyear-old child did not understand, while for Roy, recognition dawned that it was the onset of 'the long good-bye.' He asked Rosie to do what she could to highlight the impact of the disease.

At the time, she said they were both physically fit, but this is not always the case, especially with later onset or patients who may need medical interventions. Dr Tope suggested that at the point of diagnosis, all patients and their carers should be given a health MOT to ensure that they are in good health, especially their teeth, sight and hearing, before other challenges develop.

Roy's teeth were not a problem throughout his illness, she said as she paid tribute to Special Care Dentist Dr Janet Griffiths and dental hygienist Dawn Hooper. His eyes were a different matter and he needed a cataract operation, which she had to push for.

With Roy, communication gradually became more difficult. She found he wanted to express himself through sign language, such as a thumbs up or thumbs down. Other carers she spoke to had similar experiences of their loved ones using hand signs. She is now leading on the development of a project called 'Watch my needs.' In 2014 she won a Big Lottery Fund grant of $£ 46,590$ to support the project.

Through a Cardiff based organisation she is working with the Makaton Charity to train people with dementia and their carers to use sign language. Dr Tope said: 'It's been extraordinary. 200 people with dementia and their carers have attended the Watch My Needs course and we are now delivering it in care homes.'

A further development has been the creation of 'choice boards' which dementia sufferers can be given so they can indicate their preferences and needs. 'The last thing I want to get across to you is that someone with dementia, no matter how far along their journey they are, they understand what is said but cannot compute or communicate back to you.'

Dr Tope was full of optimism for the difference the new Makaton sign language and Choice Boards will make for dementia sufferers and their carers and predicted the resources should be ready to go nationwide in 2019.

'Everything I do for Carers UK and as Chair of Carers Wales I do for Roy', she said, 'and I would not have it any other way. I will champion this issue until I take my last breath?

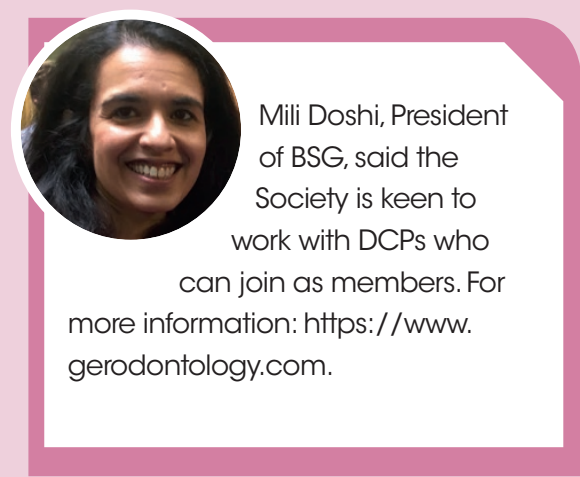

